\title{
Real-Time Anticipation and Prevention of Hot Spots by Monitoring the Dynamic Conductance of Photovoltaic Panels
}

This paper was downloaded from TechRxiv (https://www.techrxiv.org).

LICENSE

CC BY 4.0

SUBMISSION DATE / POSTED DATE

$15-10-2021 / 19-10-2021$

\section{CITATION}

Lamb, William; Asnes, Dallon; Kupfer, Jonathan; Lickey, Emma; Bakken, Jeremy; Haskell, Richard; et al. (2021): Real-Time Anticipation and Prevention of Hot Spots by Monitoring the Dynamic Conductance of Photovoltaic Panels. TechRxiv. Preprint. https://doi.org/10.36227/techrxiv.16815325.v1

$\mathrm{DOI}$

10.36227/techrxiv.16815325.v1 


\title{
Real-Time Anticipation and Prevention of Hot Spots by Monitoring the Dynamic Conductance of Photovoltaic Panels
}

\author{
William P. Lamb, Dallon E. Asnes, Jonathan Kupfer, Emma Lickey, Jeremy Bakken, Richard C. Haskell, \\ Peter N. Saeta, and Qimin Yang
}

\begin{abstract}
Hot spotting in photovoltaic (PV) panels causes physical damage, power loss, reduced lifetime reliability, and increased manufacturing costs. The problem arises routinely in defect-free standard panels; any string of cells that receives uneven illumination can develop hot spots, and the temperature rise often exceeds $100^{\circ} \mathrm{C}$ in conventional silicon panels despite onpanel bypass diodes, the standard mitigation technique. Bypass diodes limit the power dissipated in a cell subjected to reverse bias, but they do not prevent hot spots from forming. An alternative control method has been suggested by Kernahan [1] that senses in real time the dynamic conductance $|\mathrm{d} I / \mathrm{d} V|$ of a string of cells and adjusts its operating current so that a partially shaded cell is never forced into reverse bias. We start by exploring the behavior of individual illuminated PV cells when externally forced into reverse bias. We observe that cells can suffer significant heating and structural damage, with desoldering of cell-tabbing and discolorations on the front cell surface. Then we test PV panels and confirm Kernahan's proposed panellevel solution that anticipates and prevents hot spots in real time. Simulations of cells and panels confirm our experimental observations and provide insights into both the operation of Kernahan's method and panel performance.
\end{abstract}

Index Terms-hot spots, hot-spot-prevented PV panels, maximum power point trackers, photovoltaic cells, photovoltaic systems, solar power generation

\section{INTRODUCTION}

A growing body of literature recognizes the dangers of hot spots formed in photovoltaic panels as shaded cells are forced into reverse bias [2]-[16]. Bypass diodes were considered an acceptable mitigation technique prior to 2000 ,

This work was supported by Harvey Mudd College through pro bono inclusion as a project in the College's signature Clinic Program.

W.P. Lamb was with Pomona College, Claremont, CA 91711 USA. He is now with Singular Genomics, San Diego, CA 92037 USA (e-mail: wp112014@mymail.pomona.edu).

D.E. Asnes was with Pomona College, Claremont, CA 91711 USA. He is now with the Department of Computer Science, University of Chicago, Chicago, IL 60637 USA (e-mail: dasnes@uchicago.edu).

J. Kupfer is with the Department of Civil and Environmental Engineering and the Department of City and Regional Planning at the University of California, Berkeley, CA 94720 USA. (e-mail: jkupfer@berkeley.edu).

E. Lickey is a physics major at Harvey Mudd Colege, Claremont, CA 91711 USA (e-mail: elickey@g.hmc.edu).

J. Bakken is a physics major at Harvey Mudd Colege, Claremont, CA 91711 USA (e-mail: jbakken@g.hmc.edu).

R. C. Haskell is with the Department of Physics, Harvey Mudd College, Claremont, CA 91711 USA (e-mail: haskell@g.hmc.edu).

P. N. Saeta is with the Department of Physics, Harvey Mudd College, Claremont, CA 91711 USA (e-mail: saeta@g.hmc.edu).

Q. Yang is with the Department of Engineering, Harvey Mudd College, Claremont, CA 91711 USA (e-mail: yang@g.hmc.edu). but since that time the power generated on a panel has increased by a factor of three, providing three times the power to feed a hot spot.

While bypass diodes are routinely included in the design of present-day PV panels, they have been termed "inadequate" or "insufficient" to prevent hot spots in currently available high-power panels [3], [7], [13]-[15]. Multiple research groups have proposed alternative techniques to detect the onset or presence of hot spots [2]-[4], [8]-[12], and in some proposed techniques, additional actions are recommended to mitigate, prevent, or isolate hot spots [3], [4], [7], [9], [10]. We are aware of only one technique that can both sense the onset of a hot spot and take action in real time to prevent its occurrence, thereby avoiding potential damage to the panel [1]. This patented technique has negligible dead time and can continuously handle rapid changes in shading of cells.

Kernahan's technique [1] constantly monitors the dynamic conductance of a string of cells, defined as the absolute value of the local slope $\widetilde{G}=|\Delta I / \Delta V|$ at the operating point on the $I-V$ curve. (We will use a tilde to indicate the dynamic conductance, $\widetilde{g}$ for a cell and $\widetilde{G}$ for a string.) As discussed in Section III, a shaded cell that is in danger of being forced into reverse bias by the fully illuminated cells in the string exhibits a progressively smaller cell conductance, which quickly dominates the conductance of the entire string. Kernahan's technique simply adjusts the string current to keep $\widetilde{G}$ above a minimum value (see Eq. (3)) that assures that no cell in the string has entered reverse bias.

In Section II of this paper, we focus on hot spots induced in a single isolated PV cell. We describe briefly the temperature rises and damage that we observe as the cell is deliberately forced into reverse bias. Our observations are consistent with previously published research [6]. In later sections of this paper, our measurements serve as a baseline for analysis of hot spots generated in selected, representative PV panels.

Section III describes experimental tests of popular commercial PV panels whose design includes bypass diodes. Partial shading of cells on these commercial panels resulted routinely in hot spots. We also tested "hot-spot-prevented" (HSP) panels whose design does not include bypass diodes but instead incorporates Kernahan's patented solar technology [1]. Partial shading on the HSP panels never induced hot spots.

Section IV describes our modeling and computer simulations of the HSP panels. The results are consistent with the measurements of Section III, and explain several surprising 
experimental observations; e.g., partial shading of a single cell in an HSP panel causes no notable reduction in panel output power until the shading exceeds $\approx 8 \%$ of the cell.

Finally, in Section V we summarize our results and point out important simplifications of PV panel architecture enabled by HSP operation of panels-without bypass diodes.

\section{Hot Spot on AN IsOlated PV CELL}

Initial investigations of hot spots were performed on an isolated monocrystalline-Si Everbright PV cell to explore the severity of damage caused by a hot spot deliberately induced by applying reverse bias while the cell was illuminated. See Fig. 1 for an $I-V$ operating curve and equivalent DC circuit model.

We define the dynamic conductance $\widetilde{g}$ of the PV cell as the magnitude of the slope of the cell's $I-V$ curve at a given operating point,

$$
\widetilde{g}=\left|\mathrm{d} I / \mathrm{d} V_{\text {cell }}\right|
$$

Note in Fig. 1 that $\widetilde{g}$ tends toward $1 / R_{\text {shunt }}$ as the operating point moves away from the maximum power point (MPP) toward short circuit. Similarly, $\widetilde{g}$ tends toward $1 / R_{\text {series }}$ as the operating point moves toward higher voltages and open circuit. Typical values for $R_{\text {shunt }}$ and $R_{\text {series }}$ measured in our lab and reported by others [5] are a few hundred ohms and somewhat less than $0.1 \Omega$, respectively, yielding the very different slopes evident in Fig. 1 at opposite ends of the $I-V$ curve in the first quadrant.

\section{A. Experimental Setup}

Figure 2 shows a schematic of the test equipment used to characterize the $I-V$ curve of the Everbright PV cell and subsequently to force it into reverse bias. This reverse-bias condition simulated the behavior of a partially shaded cell in series with a string of fully illuminated cells.

A power supply was used to force a voltage across the terminals of the solar cell. Two $20 \mathrm{~A} 200 \mathrm{~V}$ diodes were placed in series between the power supply and the cell input terminal to create an offset $(\approx 1.3 \mathrm{~V})$, allowing the cell to be operated from open circuit $(0.6 \mathrm{~V})$ through reverse bias (as

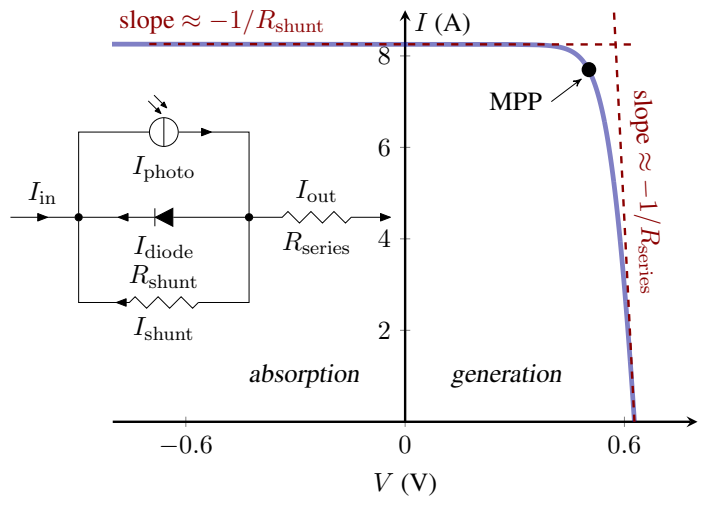

Fig. 1. Equivalent DC circuit model for a PV cell (left inset), and an $I-V$ operating curve for the Everbright grade A full-size $(156 \mathrm{~mm} \times 156 \mathrm{~mm}) \mathrm{PV}$ cell.

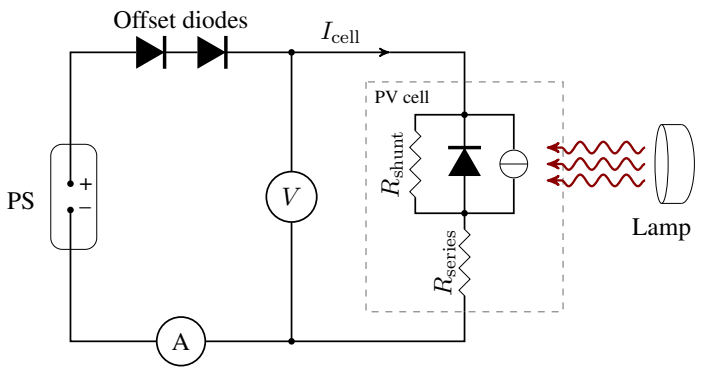

Fig. 2. Experimental setup for measuring the $I-V$ curve of a single PV cell, and subsequently observing the temperature rise and damage sustained when forced into reverse bias. PS = HP6267B power supply; V and A are two Tektronix DM2510G multimeters for measuring the cell voltage and current, respectively; the offset diodes are Diodes, Inc., SBR20A200CT; and the lamp is an ETC Source 4 Ellipsoidal $750 \mathrm{~W} 36^{\circ} 436$ spotlight.

negative as $-12 \mathrm{~V}$ ). Two multimeters were used to measure the current through and voltage across the PV cell. A Fluke infrared camera (IR Flexcam TI45) was used to record thermal images of the PV cell and provide its spatial distribution of temperature as various operating conditions were forced upon the cell.

An ETC spotlight powered by a Variac ${ }^{\mathrm{TM}}$ variable transformer was used to illuminate the solar cell. Effective onesun illumination was determined by adjusting the spotlight output to produce the cell's rated short-circuit current at onesun while the power supply imposed zero volts across the cell. Because the spotlight's spectrum differs from the Sun's, we denote this illumination as "1.0-sun-ETC." Similarly, "0.8sun-ETC" illumination was determined by adjusting the spotlight output to produce $80 \%$ of the cell's rated short-circuit current with the cell voltage held at $0 \mathrm{~V}$. This 0.8 -sun-ETC illumination was incident upon the cell when reverse bias was applied.

\section{B. Reverse Bias and Resulting Hot Spot}

Several sweeps of the $I$ - $V$ curve of the solar cell were performed, beginning at open circuit and ending at short circuit. Thermal images were taken at several operating points, including the MPP and short circuit. Finally, at the end of the last $I-V$ curve sweep, the illumination was reduced from 1.0sun-ETC to 0.8-sun-ETC and the voltage across the cell was

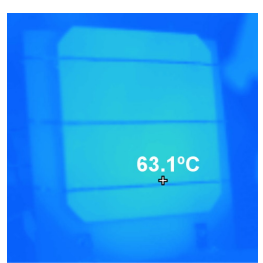

(a)

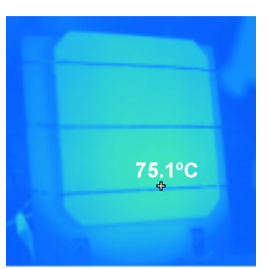

(b)

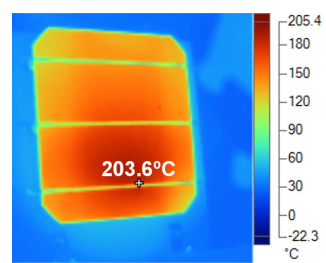

(c)
Fig. 3. Thermal images of a solar cell under three different conditions: (a) the cell near maximum power generation at $63^{\circ} \mathrm{C}$ with cell voltage $=0.38 \mathrm{~V}$ and 1.0-sun-ETC illumination, (b) the cell in short circuit at $75^{\circ} \mathrm{C}$ and 1.0 sun-ETC illumination, and (c) the cell under reverse bias at $204^{\circ} \mathrm{C}$ with cell voltage $=-12 \mathrm{~V}$ and 0.8 -sun-ETC illumination. All thermal images use the same color coding displayed on the right side of the figure. 
forced negative, eventually reaching $-12 \mathrm{~V}$ for a few minutes. The reverse bias of $-12 \mathrm{~V}$ was chosen because it is commonly experienced by a partially shaded cell in a string of 20 cells whose bypass diode has been activated [3].

While dissipating power under reverse bias, the cell heated to over $200^{\circ} \mathrm{C}$, melting the solder joints to the point of failure. A difference in thermal expansion between the metal lead tabs on the cell and the silicon wafer caused the cell to deform slightly, lifting the leads off the surface of the cell. The cell was rendered unusable until the electrical connection could be replaced and re-soldered.

Figure 3 displays three thermal images taken (a) at the MPP, (b) at short circuit, and (c) under reverse bias at $-12 \mathrm{~V}$. The temperature at the MPP is roughly uniform at $63^{\circ} \mathrm{C}$, which is elevated from ambient $\left(25^{\circ} \mathrm{C}\right)$ because of heating from the spotlight with only a fraction of that heat leaving the cell as electrical energy. However, at short circuit, the cell voltage is zero and hence, no electrical power leaves the cell and the temperature is even higher $\left(75^{\circ} \mathrm{C}\right)$. In reverse bias (c), the temperature reached $204^{\circ} \mathrm{C}$, which exceeded the melting point $\left(138^{\circ} \mathrm{C}\right)$ of the $\mathrm{Bi} 58 \mathrm{Sn} 42$ solder and disabled the cell. Notice that the transition from MPP to reverse bias of $-12 \mathrm{~V}$ raised the temperature of the cell by $140^{\circ} \mathrm{C}$ which would have melted the solder even if the beginning MPP temperature had been ambient $\left(25^{\circ} \mathrm{C}\right)$. In Section III, we describe a similar temperature rise when the cell resides in a panel string.

\section{Hot Spots IN PV PANELS}

A single shaded PV cell in a string of 20 or 24 cells can readily develop a hot spot unless the string's current is kept low enough. The scenario depicted in Fig. 4 focuses on three cells that represent a longer string. Initially all cells are fully and uniformly illuminated and hence operate at the same point of their common $I-V$ curves, typically the MPP, as shown in Fig. 4(a).

In Fig. 4(b), cell $\mathrm{PV}_{3}$ is $50 \%$ shaded, which shifts its $I-V$ curve down. A conventional controller executing a maximum power point tracking (MPPT) algorithm will attempt to maintain the prior current level and may send the operating point of $\mathrm{PV}_{3}$ into reverse bias and cause the cell to heat. A type-B cell (which begins breakdown before a reverse voltage of $-12 \mathrm{~V}$ ) may be able to supply the demanded current without activating the bypass diode (as illustrated in Fig. 4(b)), whereas a type-A cell (which begins to break down at a bias more negative than $-12 \mathrm{~V}$ ) will be driven to roughly $-12 \mathrm{~V}$ before the bypass diode activates [3]. In either case, a hot spot will result like the one shown in Fig. 3(c). The operating points of $\mathrm{PV}_{1}$ and $\mathrm{PV}_{2}$ will move to higher voltage to achieve the lower current imposed by $\mathrm{PV}_{3}$ (see Fig. 4(b)).

If instead of a conventional controller, Kernahan's procedure [1] is used to operate the string (Fig. 4(c)), $I_{\text {string }}$ is reduced to just below $I_{\mathrm{sc}}$ of $\mathrm{PV}_{3}$, while $\mathrm{PV}_{1}$ and $\mathrm{PV}_{2}$ will shift their operating point to higher voltage to match the lower current of $\mathrm{PV}_{3}$. The key point is that $\mathrm{PV}_{3}$ retains a positive bias, continues to generate power, and avoids the formation of a hot spot.

How does Kernahan's operating protocol prevent hot spots? It prevents them by mandating that the string dynamic conduc-

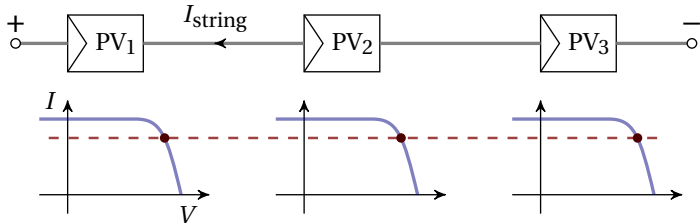

(a) Uniform illumination

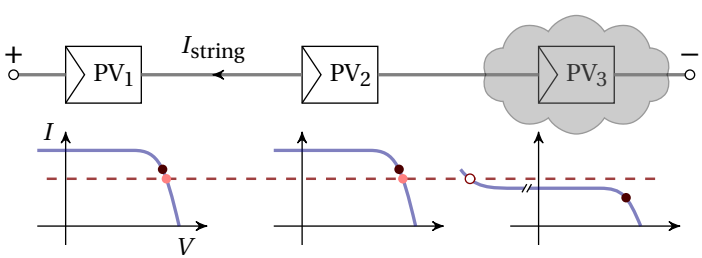

(b) Hot spot formation

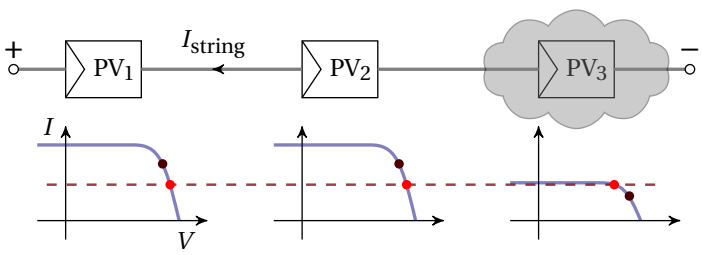

(c) Hot spot avoidance with HSP

Fig. 4. (a) Three identical, fully and uniformly illuminated PV cells in a string are operating at the same point on their common $I-V$ curves. (b) $\mathrm{PV}_{3}$ is now partially shaded, reducing its photocurrent. A conventional MPPT controller sends the $\mathrm{PV}_{3}$ operating point into reverse bias (open red dot). $\mathrm{PV} V_{1}$ and $\mathrm{PV}_{2}$ shift to higher voltage to match their current to that of $\mathrm{PV}_{3}$. (c) Kernahan's controller sets the operating current to just below $I_{\mathrm{Sc}}$ of the shaded cell, avoiding a hot spot. All Panels: Dark dots are the initial operating points and red dots are the final operating points due to the shading of $\mathrm{PV}_{3}$.

tance remain above a threshold. Note that the operating point of the shaded cell $\mathrm{PV}_{3}$ (Fig. 4(c)) has moved toward a region of its $I-V$ curve where the local slope $\widetilde{g}$ is smaller. Kernahan's procedure finds the safe operating point for the string by continually measuring $\widetilde{G}$ under microprocessor control on a millisecond time scale, and adjusting panel current using a switching power converter. As the shaded cell $\mathrm{PV}_{3}$ is forced to operate closer to its short-circuit current, its cell $\widetilde{g}$ falls significantly and comes to dominate the string $\widetilde{G}$, given by

$$
\frac{1}{\widetilde{G}}=\sum_{n=1}^{N_{\text {cells }}} \frac{1}{\widetilde{g}_{n}}
$$

When the microprocessor senses a string conductance below a preset minimum value (see Eq. (3)), the power converter decreases the string current until $\widetilde{G}$ rises above the preset minimum, indicating that no cell is in danger of approaching its short-circuit current.

\section{A. PV Panels for Testing}

Two types of panels were tested:

- a popular commercial panel (COMM) with rated MPP output power of $285 \mathrm{~W}\left(I_{\mathrm{MPP}}=8.97 \mathrm{~A}, V_{\mathrm{MPP}}=\right.$ $31.80 \mathrm{~V})$ at standard test conditions (STC) $\left(1 \mathrm{~kW} / \mathrm{m}^{2}\right.$, $25^{\circ} \mathrm{C}$, AM 1.5). See Fig. 5(a). The panel was configured with $N_{\text {cells }}=60 \mathrm{PV}$ cells (each approximately $156 \mathrm{~mm}$ square) wired in series in three strings of 20 cells each. 


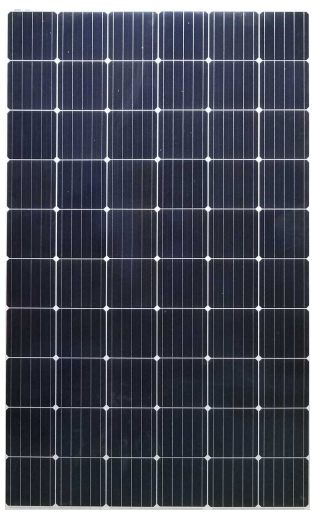

(a) COMM

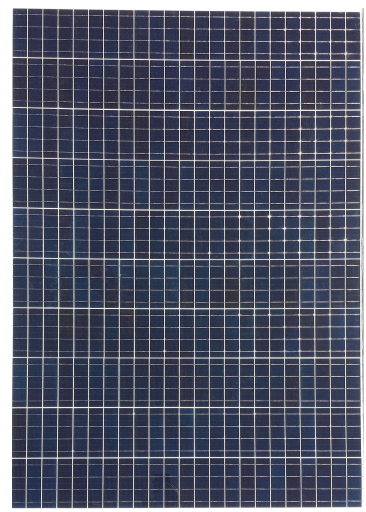

(b) HSP
Fig. 5. Two types of PV panels were tested: (a) a popular commercial panel $(\mathrm{COMM})$ with a $6 \times 10$ array of standard-size cells, and (b) a hot-spotprevented (HSP) panel with a $23 \times 10$ array of quarter-width cells.

A bypass diode was provided for each string. $I_{\mathrm{sc}}$ was specified as $9.46 \mathrm{~A}$ and $V_{\text {oc }}$ as $39.15 \mathrm{~V}$.

- a hot-spot-prevented panel (HSP) was constructed with $N_{\text {cells }}=230$ quarter-width cells $(39 \mathrm{~mm}$ wide by $156 \mathrm{~mm}$ ). The cells were cut from commercially available cells and assembled on the HSP panel in a single series string without bypass diodes. A microprocessor and dcdc power converter were located on-panel at one corner of the back side. Table I lists typical performance specifications of the HSP panel.

\section{B. Behavior of the Panels under Increasing Shading}

The commercial (COMM) panel was operated under MPPT control using an Epever Tracer 3210AN charge controller connected to a 12-V 100-Ah AGM Pb-acid battery (WindyNation RA 12-100C) and a resistive load. The load ensured that the battery voltage remained low enough that the Tracer operated in bulk-charging mode-meaning that it aimed to operate at the MPP. One cell was alternately covered with pieces of opaque foam core of increasing size and then uncovered to allow the panel to operate under full sun. The top panel of Fig. 6 shows the ratio of the panel power shaded vs. unshaded as the shaded fraction of a single cell increases (filled red circles). Between 0 and $\approx 48 \%$ shading, the panel output falls roughly quadratically with increasing shading, in good agreement with a simulation based on panel specifications and an ideal MPPT controller (red curve, see Section IV). As the controller explores small changes in current, it finds that increases in current send the shaded cell into reverse bias, where the cell's negative contribution to panel output power is significant. The controller thus demands a decreasing current in this regime of increasing shading, which keeps the shaded cell's voltage positive and its temperature roughly constant, as measured with a FLIROne Pro thermal camera and shown in the open red circles in the lower panel. At 50\% shading, however, the panel power has decreased below two-thirds of its fully illuminated value, and the MPPT controller senses that raising the current from $\approx 4.8 \mathrm{~A}$ to $\approx 8.2 \mathrm{~A}$ increases the panel output power. This causes the bypass diode of the string

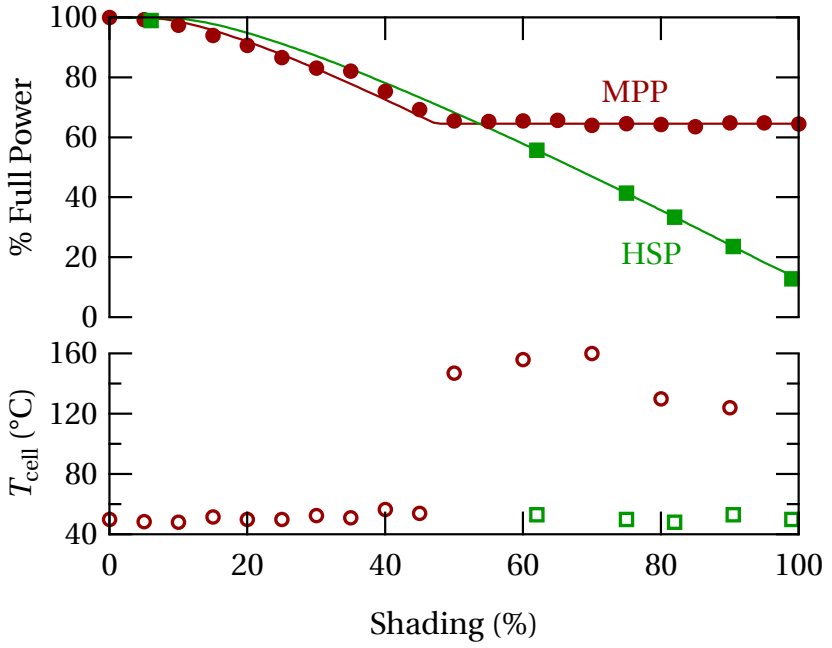

Fig. 6. Top panel: Output power as a function of percent shading of a single cell in a COMM panel under MPPT control (filled red circles) and in an HSP panel (filled green squares). In both cases, the power output with a shaded cell is normalized by the full power with the shade removed. The red curve shows a simulation of the expected behavior of the COMM panel with a lossless controller. The green curve is a simulation of expected behavior of the HSP panel as described in detail in Section IV. Bottom panel: The temperatures of the shaded cells in the COMM panel (open red circles) and in the HSP panel (open green squares) vs. shading of a single cell. The shaded COMM cell remains roughly $25^{\circ} \mathrm{C}$ above ambient as shading increases and current decreases until the shading exceeds $48 \%$. At this point, the MPPT controller raises the current, which activates the bypass diode of the string with the shaded cell. The temperature of the shaded cell then rises as high as $160^{\circ} \mathrm{C}$ for $70 \%$ shading. The shaded HSP cell (open green squares) shows no temperature rise for this high level of shading, but shows output power that decreases linearly with shading, albeit with an offset we attribute to light leaking through the back of the panel.

with the shaded cell to conduct, effectively isolating the shaded string from the rest of the panel and raising the shaded cell's temperature above $150^{\circ} \mathrm{C}$ (see Fig. 7 (a)). Further shading did not affect the output power, as the controller operated to harvest the available power of the panel's two fully illuminated strings at a current of $\approx 8.2 \mathrm{~A}$.

The HSP panel was connected to a 100-Ah deep-cycle AGM sealed $\mathrm{Pb}$-acid battery pack consisting of four $12-\mathrm{V}$ batteries (WindyNation NSAP 12-100) connected in series to achieve a nominal voltage of $48 \mathrm{~V}$. Initially, one of the 230 cells was shaded by $62 \%$ with black electrical tape while the panel current and voltage were monitored with multimeters. The green squares in Fig. 6 (upper panel) show that the panel's output power fell linearly as shading increased from $62 \%$ to nearly $100 \%$, as one would expect for a linear decrease in the panel current to match the diminished photocurrent of the shaded cell. Furthermore, the shaded cell's temperature remained low (lower panel) since the HSP controller kept the current low enough to avoid reverse bias in the shaded cell.

To a good approximation, the response of the HSP panel to shading of a single cell between 0 and $48 \%$ is quite similar to that of the conventional panel. Both are under MPPT control and both lower the current in response to shading. However, above $48 \%$ shading, the behavior diverges, with the output of the HSP panel continuing to drop linearly, whereas the conventional panel's output remains constant at slightly below 


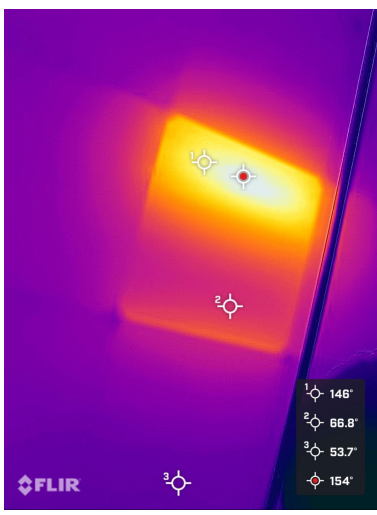

(a) COMM

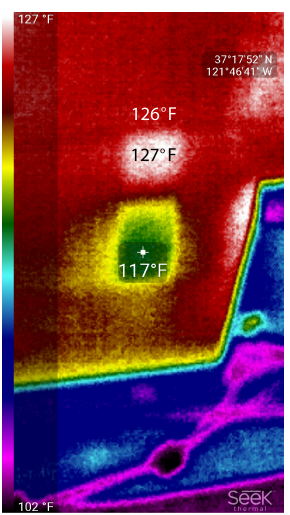

(b) HSP
Fig. 7. (a) Thermal image of the shaded cell on a COMM panel documenting a hotspot of $154^{\circ} \mathrm{C}$. (b) Thermal image of a HSP panel showing a temperature of $117^{\circ} \mathrm{F}\left(47^{\circ} \mathrm{C}\right)$ on the shaded portion (green) of the shaded cell. A temperature of $127^{\circ} \mathrm{F}\left(53^{\circ} \mathrm{C}\right)$ is recorded on the illuminated portion (upper, white) of the shaded cell, and a temperature of $126^{\circ} \mathrm{F}\left(52^{\circ} \mathrm{C}\right)$ is recorded on an unshaded neighboring cell located just above the shaded cell.

$65 \%$ (down from $2 / 3$ since the voltage output of the two functioning strings is reduced by $\mathrm{a} \approx 0.6 \mathrm{~V}$ drop across the bypass diode). Herein lies the essential tradeoff: the HSP panel sacrifices a modest amount of energy production under strong shading conditions (> 48\%) to prevent the shaded cell from entering reverse bias, whereas the conventional panel uses bypass diodes to isolate and exclude the shaded string to allow the fully illuminated strings to operate at their MPP. However, the bypassed string now almost certainly contains a cell with a hot spot of $160^{\circ} \mathrm{C}$ or more. We note that DuPont ${ }^{\mathrm{TM}}$ approves the continuous use of Tedlar ${ }^{\circledR}$ PVF film as a backsheet in photovoltaic panels up to a maximum temperature of $107^{\circ} \mathrm{C}$ [17].

Thus far, we have compared the response of single panels, whether of conventional construction under MPPT control or of HSP type. Typical rooftop solar installations combine the output of $N_{p}=10$ to 20 panels or more wired in series. Assuming that the conventional panels use power optimizers, each panel is controlled by its own MPPT controller and functions essentially independently of the other panels. However, the output of the array is orchestrated by a central MPPT controller that is typically attached to an inverter to connect to the grid [18], [19]. An analogous HSP PV panel array has the same structure; the HSP controllers serve as MPPT optimizers, but they have an overriding mandate to prevent any cell from entering reverse bias. A central MPPT controller again operates the entire array. Therefore, comparing an array of conventional panels with power optimizers to an array of HSP panels reduces to the single-panel comparison we described above.

\section{Modeling of PV Cells and PANels}

To gain a deeper understanding of the performance of the HSP panel, especially at the cell level which is cumbersome to measure directly, we have simulated the response of a string of 230 cells to partial shading while under the control of the Kernahan algorithm. We use a static version of the

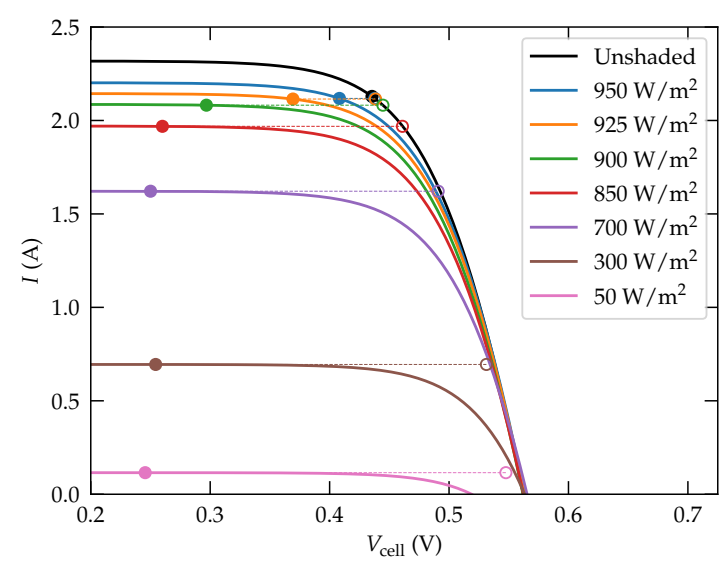

Fig. 8. $I-V$ curves of the unshaded cells (black) and a single shaded cell subjected to varying levels of illumination. The black dot indicates the MPP when no cells are shaded; the filled dots show the operating point of the shaded cell, while the open dots on the unshaded $I-V$ curve show the corresponding operating point of the unshaded cells. The model uses the measured value $R_{\text {shunt }}=2268 \Omega$ to characterize $\widetilde{g}$ at short circuit.

cell model elaborated in Ref. [5], ignoring capacitive and inductive effects that are negligible below $1 \mathrm{kHz}$. For a given illumination, the model calculates the photocurrent $I_{\text {photo }}$ in Fig. 1 and includes temperature-dependent effects. Then for a given $I_{\text {cell }}$, the model solves iteratively for the voltage across the diode and shunt resistor in Fig. 1, which finally yields the voltage across the cell. We further assume that each cell has achieved its steady-state temperature rise under all operating conditions, using a temperature rise with respect to ambient of $30^{\circ} \mathrm{C}$ for $1 \mathrm{~kW} / \mathrm{m}^{2}$ net power deposited. The string of 230 series-connected quarter-width PV cells is then subjected to nonuniform illumination. See Table I for parameters and values used in the simulations.

As an initial example, consider a single cell to be shaded to varying degrees, while the remaining 229 cells receive full irradiance of $1 \mathrm{~kW} / \mathrm{m}^{2}$. Figure 8 shows the $I-V$ curve of the unshaded cells (black) and the $I-V$ curves of the shaded cell for several degrees of shading. The operating point of the string (panel) for each shading condition is determined by seeking the MPP and comparing the new string dynamic conductance $\widetilde{G}_{\mathrm{MPP}}$ to a preset minimum, defined by

$$
\widetilde{G}_{\min }=\frac{\widetilde{G}_{\mathrm{MPP}_{0}}}{M}=\frac{\widetilde{g}_{\mathrm{MPP}_{0}}}{M N_{\text {cells }}}
$$

where $N_{\text {cells }}=230$ is the total number of cells in the string (panel), $\widetilde{G}_{\mathrm{MPP}_{0}}$ is the dynamic conductance of the uniformly

TABLE I

SIMULATION PARAMETERS AND VALUES

\begin{tabular}{llll} 
cell height & $156 \mathrm{~mm}$ & cell width & $39 \mathrm{~mm}$ \\
nom. irrad. & $1000 \mathrm{~W} / \mathrm{m}^{2}$ & nom. temp. & $25^{\circ} \mathrm{C}$ \\
$I_{\mathrm{MPP}}$ & $2.119 \mathrm{~A}$ & $V_{\mathrm{MPP}}$ & $100.6 \mathrm{~V}$ \\
\hline$P_{\mathrm{MPP}}$ & $213.2 \mathrm{~W}$ & diode ideality & 1.331 \\
$I_{\mathrm{Sc}}$ & $2.315 \mathrm{~A}$ & $V_{\text {oc }}$ & $0.6383 \mathrm{~V}$ \\
$R_{\text {shunt }}$ & $2268 \Omega$ & $R_{\text {series }}$ & $14.57 \mathrm{~m} \Omega$ \\
\hline$I_{\text {temp coeff }}$ & $0.1 \mathrm{~mA} / \mathrm{K}$ & $V_{\text {temp coeff }}$ & $-2.2 \mathrm{mV} / \mathrm{K}$ \\
heating coeff & $30^{\circ} \mathrm{C} \cdot \mathrm{m}^{2} / \mathrm{kW}$ & &
\end{tabular}



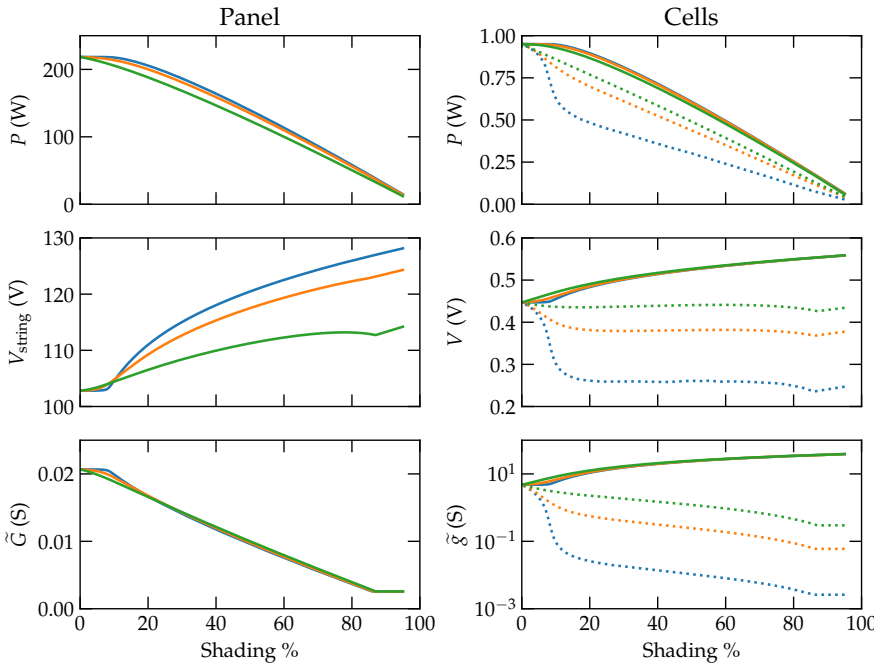

Fig. 9. Response of a 230-cell string under 1-sun illumination when 1 (blue), 23 (orange), or 115 (green) cells are shaded by the percentage indicated on the horizontal axis. The left column describes the full panel; the right column shows properties of individual cells, with the unshaded cells in solid curves and the shaded cell(s) in dotted curves.

illuminated panel at the MPP, and $M=8$ is the (somewhat arbitrary-see below) factor by which $\widetilde{G}_{\mathrm{MPP}_{0}}$ may be reduced before signaling a dangerous approach to $I_{\mathrm{sc}}$ for one or more cells. If at the newly found MPP, $\widetilde{G}_{\mathrm{MPP}} \geq \widetilde{G}_{\text {min }}$, then the new operating point is indeed set to the MPP. If, instead, $\widetilde{G}_{\mathrm{MPP}}<$ $\widetilde{G}_{\text {min }}$, the string current is decreased until the new operating point satisfies $\widetilde{G}_{\text {op }} \geq \widetilde{G}_{\min }$.

For shadings of $5 \%, 7.5 \%$, and $10 \%$ of a single cell (the blue, orange, and green curves of Fig. 8), the operating current is reduced by $0.05 \%, 0.25 \%$, and $2.0 \%$, respectively, from the fully illuminated condition. Figure 8 shows clearly what is happening. The operating point of the shaded cell moves off its MPP toward higher current and lower voltage, while the 229 unshaded cells move off their MPP toward slightly higher voltage to match the current of the shaded cell. The resulting panel voltage increases are $0.02 \%, 0.17 \%$, and $1.7 \%$, yielding remarkably small decreases in panel power of $0.03 \%, 0.08 \%$, and $0.37 \%$.

Figure 9 shows in greater detail how the performance of the string is affected by shading of one or more cells. The blue curves in the left column show the behavior of the string when a single cell receives reduced irradiance, which is the situation modeled in Fig. 8. The orange and green curves show the performance when $10 \%$ and $50 \%$, respectively, of the cells are shaded to the degree shown on the horizontal axis.

As seen in the blue curve of the bottom-left panel of Fig. 9, after remaining roughly constant for shading up to about $10 \%$, $\widetilde{G}$ falls roughly linearly as shading increases beyond $10 \%$, arriving at $\widetilde{G}_{\min }$ at about $87 \%$ shading. Up to this point, the controller operates the string at its MPP, lowering the string current to keep the shaded cell from approaching the nearly flat region of its $I-V$ curve. The response of both unshaded (solid curves) and shaded (dotted curves) cells is shown in the right-hand column of Fig. 9. By $10 \%$ shading of a single cell (blue curves), the voltage of the shaded cell has dropped significantly (middle panel) and the cell dynamic conductance $\widetilde{g}_{\text {shaded }}$ has dropped by a factor of 100 . The string dynamic conductance does not show a precipitous drop because the modest increase in $\widetilde{g}_{\text {unshaded }}$ applies to all 229 unshaded cells, largely compensating the steep decline in $\widetilde{g}_{\text {shaded }}$. For shading in excess of $87 \%$, the string must be operated not at the MPP but at $\widetilde{G}=\widetilde{G}_{\min }$, as illustrated by the flat portion of the curves of both $\widetilde{G}$ and $\widetilde{g}_{\text {shaded }}$.

Finally, it is important to highlight a requirement for the success of Kernahan's method for avoiding hot spots:

$$
\frac{1}{R_{\text {shunt }}} \ll \widetilde{G}_{\mathrm{MPP}_{0}}=\frac{\widetilde{g}_{\mathrm{MPP}_{0}}}{N_{\text {cells }}}
$$

If $R_{\text {shunt }}$ of the cells is too small or $N_{\text {cells }}$ is too large, the limiting dynamic conductance $\approx 1 / R_{\text {shunt }}$ of any shaded cell as it approaches short-circuit may be larger than the initial value of the string dynamic conductance $\widetilde{G}_{\mathrm{MPP}_{0}}$. In this unfortunate circumstance, shading of any cell(s) may not decrease $\widetilde{G}$, and there is no choice for $\widetilde{G}_{\min }$ below which a cell's decreasing $\widetilde{g}$ is guaranteed to trigger a decrease in string current that will prevent the shaded cell from slipping into reverse bias.

For example, in the case of shading just a single cell, described in Figs. 8 and 9, the starting dynamic conductance $\widetilde{G}_{\mathrm{MPP}_{0}}$ of the fully and uniformly illuminated string is $21 \mathrm{mS}$, while the minimum cell conductance is $1 / R_{\text {shunt }}=0.44 \mathrm{mS}$, providing a factor of 48 reduction from $\widetilde{G}_{\mathrm{MPP}_{0}}$. We chose $M=8$ in Eq. (2) to place $\widetilde{G}_{\min }$ at $2.6 \mathrm{mS}$, comfortably between the starting value and a value indicating approach to reverse bias for at least one cell. This broad range for $\widetilde{G}$ allows for noise in the measurements of $\widetilde{G}$ and even allows for a large number of cells $\left(N_{\text {cells }}=230\right)$ in the string (panel).

\section{Discussion}

During the past decade, a body of research has aimed to retain full power generation from unshaded cells even when they are in series with shaded cells [20]-[23]. Sophisticated power electronics have been deployed in a technique called Differential Power Processing (DPP). We believe the cost and stability of these DPP systems present challenges to the widespread use of the technique. By contrast, Kernahan's real-time method for preventing hot spots in PV panels is commercially viable and we have experimentally demonstrated its effectiveness. By trading current for voltage, the method reduces on-panel ohmic losses, and it relaxes manufacturing constraints on cell uniformity and the need for expensive heatresistant glass coverings, but a head-to-head comparison of their output power with that from conventional panels under a variety of shading conditions is still needed and is in process.

\section{REFERENCES}

[1] K. Kernahan, "Idealized Solar Panel," United States Patent 8952672 , Feb. 10, 2015.

[2] K. A. Kim, G.-S. Seo, B.-H. Cho, and P. T. Krein, "Photovoltaic Hot-Spot Detection for Solar Panel Substrings Using AC Parameter Characterization," IEEE Transactions on Power Electronics, vol. 31, no. 2, pp. 1121-1130, Sep. 2015.

[3] Kim, Katherine A and Krein, Philip T, "Reexamination of Photovoltaic Hot Spotting to Show Inadequacy of the Bypass Diode," IEEE Journal of Photovoltaics, vol. 5, no. 5, pp. 1435-1441, Aug. 2015. 
[4] Kim, Katherine A, Ehlmann, Jonathan, and Krein, Philip T, "Photovoltaic Hot Spot Mitigation Using Voltage-Threshold Control at the Panel Level,” 2015 9th International Conference on Power Electronics and ECCE Asia (ICPE-ECCE Asia), pp. 1916-1921, Jun. 2015.

[5] Kim, Katherine A, Xu, Chenyang, Jin, Lei, and Krein, Philip T, "A Dynamic Photovoltaic Model Incorporating Capacitive and Reverse-Bias Characteristics," IEEE Journal of Photovoltaics, vol. 3, no. 4, pp. 13341341, Sep. 2013.

[6] Kim, Katherine A and Krein, Philip T, "Hot Spotting and Second Breakdown Effects on Reverse I-V Characteristics for Mono-Crystalline Si Photovoltaics," 2013 IEEE Energy Conversion Congress and Exposition, pp. 1007-1014, Jul. 2013.

[7] _ _ "Photovoltaic Hot Spot Analysis for Cells with Various ReverseBias Characteristics Through Electrical and Thermal Simulation," 2013 IEEE 14th Workshop on Control and Modeling for Power Electronics (COMPEL), pp. 1-8, Jun. 2013.

[8] K. A. Kim, P. T. Krein, G.-S. Seo, and B.-H. Cho, "Photovoltaic AC Parameter Characterization for Dynamic Partial Shading and Hot Spot Detection," in IEEE Applied Power Electronics Conference and Exhibit, Long Beach, California, USA, Mar. 2013, pp. 109-115.

[9] Ghanbari, Teymoor, "Hot Spot Detection and Prevention Using a Simple Method in Photovoltaic Panels," IET Generation, Transmission \& Distribution, vol. 11, no. 4, pp. 883-890, Mar. 2017.

[10] _ , "Permanent Partial Shading Detection for Protection of Photovoltaic Panels Against Hot Spotting," IET Renewable Power Generation, vol. 11, no. 1, pp. 123-131, Jan. 2017.

[11] Karimi, Mohsen, Samet, Haidar, Ghanbari, Teymoor, and Moshksar, Ehsan, "A Current Based Approach for Hotspot Detection in Photovoltaic Strings," International Transactions on Electrical Energy Systems, vol. 30, no. 9, pp. 414-18, Jul. 2020.

[12] Dhimish, Mahmoud and Badran, Ghadeer, "Photovoltaic Hot-Spots Fault Detection Algorithm Using Fuzzy Systems," IEEE Transactions on Device and Materials Reliability, vol. 19, no. 4, pp. 671-679, Dec. 2019.

[13] F. Fertig, S. Rein, M. Schubert, and W. Warta, "Impact of Junction Breakdown in Multi-Crystalline Silicon Solar Cells on Hot Spot Formation and Module Performance," in th European PV Solar Energy Conference and Exhibition, Hamburg, Germany, Sep. 2011, pp. 1-12.

[14] Q. Zhang and Q. Li, "Temperature and Reverse Voltage across a Partially Shaded Si PV Cell under Hot Spot Test Condition," in IEEE 38th Photovoltaic Specialists Conference, Jun. 2012, pp. 1-4.

[15] Lee, Ji Eun, Bae, Soohyun, Oh, Wonwook, Park, Hyomin, Kim, Soo Min, Lee, Dongho, Nam, Junggyu, Mo, Chan Bin, Kim, Dongseop, Yang, JungYup, Kang, Yoonmook, Lee, Hae-seok, and Kim, Donghwan, "Investigation of Damage Caused by Partial Shading of $\mathrm{CuIn}_{x} \mathrm{Ga}_{(1-x)} \mathrm{Se}_{2}$ Photovoltaic Modules with Bypass Diodes," Progress in Photovoltaics: Research and Applications, vol. 24, no. 8, pp. 1035-1043, Apr. 2016.

[16] Sánchez-Friera, Paula, Piliougine, Michel, Peláez, Javier, Carretero, Jesús, and Sidrach de Cardona, Mariano, "Analysis of degradation mechanisms of crystalline silicon PV modules after 12 years of operation in Southern Europe," Progress in Photovoltaics: Research and Applications, vol. 19, no. 6, pp. 658-666, Jan. 2011

[17] DuPont, "DuPont Tedlar Polyvinyl Fluoride (PVF) Films-General Properties," https://www.dupont.com/solar-photovoltaic-materials/ tedlar-backsheets.html, Apr. 2014.

[18] M. Vitelli, "On the Necessity of Joint Adoption of both Distributed Maximum Power Point Tracking and Central Maximum Power Point Tracking in PV Systems," Progress in Photovoltaics: Research and Applications, vol. 22, no. 3, pp. 283-299, 3 2014. [Online]. Available: https://onlinelibrary.wiley.com/doi/10.1002/pip.2256

[19] M. Balato and M. Vitelli, "A New Control Strategy for the Optimization of Distributed MPPT in PV Applications," International Journal of Electrical Power \& Energy Systems, vol. 62, p. 763-773, 112014.

[20] H. Jeong, H. Lee, Y.-C. Liu, and K. A. Kim, "Review of Differential Power Processing Converter Techniques for Photovoltaic Applications," IEEE Transactions on Energy Conversion, vol. 34, no. 1, pp. 351-360, Mar. 2019.

[21] C. Olalla, C. Deline, D. Clement, Y. Levron, M. Rodriguez, and D. Maksimovic, "Performance of Power-Limited Differential Power Processing Architectures in Mismatched PV Systems," IEEE Transactions on Power Electronics, vol. 30, no. 2, pp. 618-631, Sep. 2014.

[22] C. Olalla, M. Hasan, C. Deline, and D. Maksimovic, "Mitigation of HotSpots in Photovoltaic Systems Using Distributed Power Electronics," Energies, vol. 11, no. 4, pp. 726-16, Apr. 2018.

[23] P. S. Shenoy, B. Johnson, and P. T. Krein, "Differential power processing architecture for increased energy production and reliability of photo- voltaic systems," in 2012 Twenty-Seventh Annual IEEE Applied Power Electronics Conference and Exposition (APEC), 2012, pp. 1987-1994.

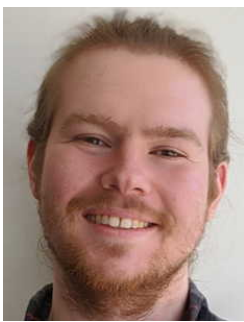

William P. Lamb received the B.A. degree in physics from Pomona College, Claremont, CA, USA in 2018. In 2019 he was a Substitute Electronics Lab Technician at Pomona College. Since the summer of 2019, he has been a research engineer at Singular Genomics, San Diego, developing next-generation sequencing instruments. Mr. Lamb has been a member of Sigma Xi since 2018.

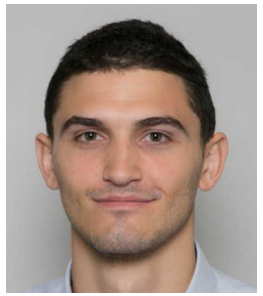

Dallon E. Asnes was born in Boca Ragton, FL, USA in 1996. He received the B.A. degree in physics from Pomona College in 2018 and the M.S. degree in Computer Science from the University of Chicago in 2020 .

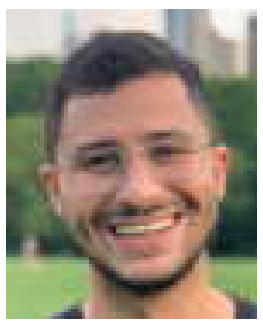

Jonathan Kupfer was born in New York City in 1996. He received the B.S. degree in engineering from Harvey Mudd College in Claremont, CA, USA in 2018. He is currently pursuing the M.S. in transportation engineering and the Master of City Planning from the University of California, Berkeley in Berkeley, CA, USA. He is passionate about improving urban transportation systems to make communities more equitable, sustainable, and livable.

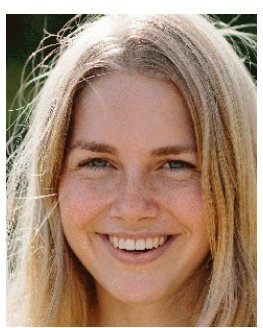

Emma Lickey is a joint math-physics major in the class of 2023 at Harvey Mudd College, Claremont, CA, USA. She is looking forward to continuing research in renewable energy systems.

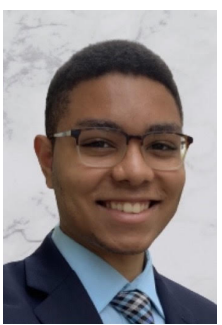

Jeremy Bakken is a member of the Class of 2023 at Harvey Mudd College in Claremont, CA, USA. $\mathrm{He}$ is currently pursuing a B.S. degree in physics and has an interest in clean energy technologies. 


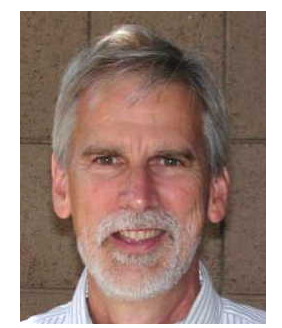

Richard C. Haskell (M'20) received the B.S. degree in engineering physics from Lehigh University in Bethlehem, PA, USA in 1967 and the Ph.D. degree in physics from The Johns Hopkins University in Baltimore, MD, USA in 1972.

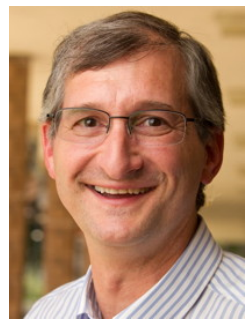

Peter N. Saeta received the B.S. degree in physics from Stanford University in Stanford, CA, USA in 1982 and the Ph.D. degree in physics from Harvard University in Cmabridge, MA, USA in 1991.

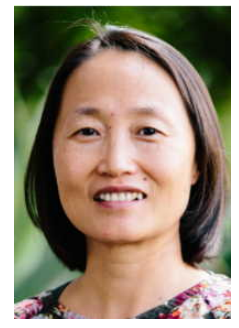

Qimin Yang received the B.S. in electrical engineering from Zhejiang University in 1994, the M.S. in electrical engineering from Beijing University of Posts and Telecommunications in 1997, and the $\mathrm{Ph} . \mathrm{D}$. degree in electrical engineering from Princeton University in 2002. Since 2002, she has been a faculty member in the Engineering Department at Harvey Mudd College. 